recently were regarded as reasonable ways of tackling some of the problems that plainly exist in the NHS. Introducing medical audit, developing better information systems, devolving budgets to doctors whose decisions commit the expenditure of public money, revising the element of cross boundary flows in the RAWP (Resource Allocation Working Party) formula, searching for ways of rewarding rather than penalising productive hospitals, and controlling excessive prescribing are all activities that have been debated for some time, and most have been issues in which doctors have been prominent in pushing for change. The white paper's proposals in these matters may not be sufficiently detailed or wholly practicable, but there should be debate about their merits as instruments of change.

Thus it would be wrong to reject parts of the white paper that are merely building on trends already underway without making alternative suggestions for tackling the important problems they deal with, although the service has not been encouraged to respond critically and selectively to different proposals. But the government should also recognise why its white paper has aroused such antagonism and seek to answer its critics with detailed evidence and argument rather than bland reassurance. The central notion of the internal market might be made to work for the benefit of patients in certain circumstances, but the evidence-for example, from a series of demonstration projects - needs to be assembled before its national introduction. It is with the aim of raising the debate that the $B M F$ has published the series of articles that concludes today. (The series is to be published as a book that will be available by 8 May.) Perhaps the time has come for the posturing to stop and the detailed discussions to start. Otherwise the NHS and those whom it serves may become victims of the verbal cross fire.

J R BUTLER

Professor of Health Services Studies,

University of Kent at Canterbury,

Canterbury,

Kent CT2 7NF

1 Secretaries of State for Health, Wales, Northern Ireland, and Scotland. Working for patients. London: HMSO, 1989. (Cmnd 555.)

2 HM Treasury. The government's expenditure plans 1989-90 to 1991-92. London: HMSO, 1989. (Cmnd 614.)

\title{
Overuse injuries in musicians
}

\section{Although they cause much distress, their aetiology and treatment remain controversial}

Musicians suffer from all sorts of occupational ills, many of them well documented. Schumann's hand injury, possibly neurological, caused him to concentrate on composition. 'The remarkable laxity of Paganini's hand, possibly due to a hereditary connective tissue abnormality, gave him a technical advantage over his contemporaries. ${ }^{2}$ And there have been diverting accounts of cor anglais player's thumb, cymbal player's shoulder, pianist's cramp, and horn player's palsy. ${ }^{3}$

Nevertheless, delightful as they are, these case reports have diverted attention from the commonest complaint of many musicians: the repetitive overuse syndrome. This has been extensively described in Australia ${ }^{+6}$ but the problem occurs all over the world. Thus similar reports have come from special music clinics in the United States (P H Caldron et al, abstract to scientific meeting of the American Rheumatism Association, 1985) ${ }^{7}$ and from a study of eight orchestras from several countries, where the findings were uniform and independent of national bias. ${ }^{8}$ Clinical grading may be applied to the overuse syndrome. ${ }^{+}$Features vary from grade 1 (pain at one site on activity) through increasing degrees of disability to grade 5 (loss of capacity to use because of continuous pain associated with loss of muscle function). The treatment differs little from that initially recommended by Poore in 1887 on the basis of a careful study of 21 pianists with symptoms in the hands and wrists that he attributed to muscular strain. ${ }^{9} \mathrm{~A}$ central feature of treatment is "rest," but does this mean a simple change in technique or complete abstinence from movement? Poore's comment that "directly they feel in a small degree better, they fly to the piano" reflects the reaction of most musicians today as it did then. Reassurance, a sympathetic ear, and sometimes treatment with anxiolytics or $\beta$ blockers have all been advocated.

The cause of the overuse syndrome in musicians remains controversial. Although some music students have been found to have laxer joints than others ${ }^{10}$ such a difference probably accounts for only a fraction of the problem. ${ }^{\text {"O Other }}$ factors may be the dominance of one side, giving an asymmetry in muscle weight, ${ }^{12}$ and fatigability. ${ }^{13}$ Different patterns of symptoms are caused by different instruments, and players may act as their own controls, particularly when, as in string players, the function of the two arms is different..$^{14}$ A recent study compared biopsy findings in the first dorsal interosseous muscle in 29 women with the painful chronic overuse syndrome with those in the same muscle from eight volunteer controls. ${ }^{15}$ Patients with the overuse syndrome all showed an increase in type 1 fibres with type grouping, decreased and hypertrophied type 2 fibres, and an increased number of nuclei and mitochondria. Such changes were different from those seen in disuse atrophy, though ethical considerations made it impossible to study a group of patients or musicians who were performing identical work without developing the overuse syndrome. Some neurologists have attributed almost half of the complaints to "inflammatory disorder of the tendons"; ; rheumatologists, less convinced that synovial proliferation is present, have preferred to draw an analogy to the focal dystonia of writer's cramp. ${ }^{16}$ Smythe believes that all the repetitive strain syndrome in the arm is referred pain from the neck. ${ }^{17}$ Others have suggested that hyperventilation ${ }^{18}$ or even anxiety is the cause, given that the syndrome can be exacerbated by stress. Nevertheless, characteristically the symptoms can be induced by a particular repetitive technical task and are relieved by rest, only to return when the technique is repeated-findings that strongly support a mechanical aetiology, at least as an initiating event.

Recently the repetitive strain syndrome in non-musicians has reached epidemic proportions in Australia. ${ }^{1920}$ The workers' compensation system allows payments of a lump sum for such a work related disease, and patients have an obvious financial benefit in getting the diagnosis established; thus the cost of repetition strain injury in Australia is now estimated to be over $\$ A 1$ billion. The resultant turmoil in the courts has led the Royal Australasian College of Physicians to advocate using the term "regional pain syndrome." ${ }^{21}$ Clearly, physiological, pathological, psychological, and psychosocial 
factors all contribute, and perhaps a more detailed comparative study of musicians who are not motivated towards compensation would throw light on the basic processes underlying these occupational health syndromes in general. The results of such a study would also benefit the musicians.

Senior Lecturer in Rheumatology,

HOWARD BIRD

University of Leeds, Leeds LS2 9JT

1 Henson RA, Urich H. Schumann's hand injury. Br Med f 1978;i:900-3.

2 Smith RD. Paganini's hand. Atthritis Rheum 1982;25:1385-6.

3 Ziporyn T. Pianist's cramp to stage fright, the medical side of music making. JAMA 1984;252:985-9.

4 Fry HJH. Overuse syndrome in musicians: prevention and management. Lancet 1986;ii:728-31.

Fry HJH. The treatment of overuse syndrome in musicians. Results in 175 patients. $\mathcal{F} R$ Soc Med 1988;81:572-5.

6 Fry HJH. Patterns of over-use seen in 658 affected instrumental musicians. International fournal of Music Education 1988;11:3-16.
7 Hochberg FH, Leffert RD, Heller MD, Merriman L. Hand difficulties among musicians. $\mathcal{F} A M A$ 1983;249:1869-72.

8 Fry HJH. Incidence of overuse syndrome in the symphony orchestra. In: Medical problems of performing artists. Philadelphia: Hanley and Belfus, 1986:51-5.

performing artists. Philadelphia: Hanley and Belfus performance of professional acts, especially piano playing. Br Med f 1887;i:441-4.

10 Larsson L-G, Baum J, Mudholkar GS. Hypermobility: features and differential incidence between the sexes. Arthritis Rheum 1987;30:1426-30.

11 Bird HA, Wright V. Traumatic synovitis in a classical guitarist: a study of joint laxity Ann Rheum Dis 1981;40:160-3.

12 Chibber SR, Singh I. Asymmetry in muscle weight and one-sided dominance in the human lower limbs. F Anat 1970;106:553-6.

13 Stokes MJ, Cooper RG, Edwards RHT. Normal muscle strength and fatigability in patients with effort syndromes. Br Med F 1988;297: 1014-6.

14 Beighton P, Grahame R, Bird H. Hypermobility of joints. Berlin: Springer, 1983.

15 Dennett X, Fry HJH. Overuse syndrome: a muscle biopsy study. Lancet 1988;i:905-8.

16 Sheehy MP, Marsden CD. Writer's cramp-a focal dystonia. Brain 1982;105:461-80.

17 Smythe H. The "repetitive strain injury syndrome" is referred pain from the neck. $f$ Rheumatol 1988;15:1604-8.

18 Nixon PGF. Overuse syndromes in musicians. Lancet 1986;ii:917.

18 Nixon PGF. Overuse syndromes in musicians. Lancet 1986;11:917.

20 National Occupational Health and Safety Commission. Repetition strain injury: a report and model code of practice. Canberra: NOHSC, 1986.

21 Brooks PM. Repetition strain injury. Lancet 1987;ii: 738

\section{Medical defence peace}

\section{Agreement needed on who gives advice on what}

This week a new defence society - the Medical Practitioners Defence Society - is due to be launched. This follows the announcement that the NHS will take over financial responsibility for medical negligence by all doctors employed by the hospital and community services. ${ }^{12}$ General practitioners and doctors in private practice, including such activities as occupational health, will still need insurance, but even hospital doctors not doing private work would be wrong to think that the vexed issue of medical negligence is finished.

The number of actions against doctors and the sizes of the awards have both grown substantially in the past few years and may well continue to do so. ${ }^{3}$ Doctors will still have to appear in the courts, and one worry is that in the past health authorities have chosen to settle a case because it is cheaper than fighting - even though the doctor's reputation may not be vindicated. The defence societies, in contrast, have at least in theory chosen to fight or settle cases on their merits rather than on which is the cheapest option. The converse anxiety is that health authorities have often not paid up promptly when there is clear evidence of fault; rather they have conformed with the long and disgraceful tradition of Crown lawyers of delaying and prevaricating in the hope that the plaintiff will give up in despair. There are also questions about whether health authorities may use indemnity as a way of backing particular forms of patient management and about whether they have adequate numbers of legal advisers of sufficiently high quality.

From the patient's point of view little is gained by health authorities offering doctors indemnity. They will still have to tackle a legal system that is slow, inefficient, adversarial, expensive, intimidating, and unfair. Doctors should continue to support no fault compensation for the sake of their patients; they should not lose interest now because their pockets are less threatened. Doctors also need to continue to examine complaints procedures because patients are commonly more interested in an explanation than in financial compensation.

Finally, the defence societies (both old and new) and the BMA must get together to delineate the boundaries of their interests. The public slanging match between the Medical Defence Union and the Medical Protection Society has been embarrassing and has not improved the image of either organisation, and has done no service to doctors. Traditionally the BMA has advised doctors on their terms and conditions of service, on their obligations to partners and colleagues, and on professional ethics. The medical defence organisations have advised on all medicolegal questions, including both the civil and criminal law. Agreement on the provision of professional advice should now be the priority for doctors and their organisations. Competition to provide similar services will have few advantages; conflicting advice benefits no one except the lawyers.

TONY SMITH

Deputy editor, $B M \mathcal{F}$

1 Department of Health. Medical defence subscriptions. London: Department of Health, 1989. 2 Beecham L. NHS indemnity. Br Med f 1989;298:852.

Dedical negligence: addressing the issues. London: MPS, 1989. 4 Delamothe T. Defence wars. Br Med f 1989;298:699-700. 